LAFER, Celso. 2001. A identidade internacional do Brasil e a politica externa brasileira. Passado, presente e futuro. São Paulo : Perspectiva.

\title{
IDENTIDADE (INTER)NACIONAL E POLÍTICA EXTERNA DO BRASIL
}

\author{
Gustavo Biscaia de Lacerda \\ Universidade Federal do Paraná
}

\begin{abstract}
Recém-empossado Chanceler, pela segunda vez, Celso Lafer escreveu o livro $A$ identidade internacional do Brasil e a política externa brasileira (2001). De pequenas dimensões, com cerca de apenas 120 páginas, a obra pretende-se "um balanço de [suas] pesquisas e reflexões de muitos anos sobre a política externa brasileira [PEB], adensado pela [sua] experiência diplomática na década de 1990" (p. 13). Ou seja, é para a obra ser uma síntese de suas idéias sobre a PEB: entretanto, mais que voltada para o passado, a partir de uma reflexão intelectual, a obra projeta-se para o futuro, sendo muito mais um programa político do atual Chanceler.
\end{abstract}

O autor, formado em Direito no Largo de São Francisco em São Paulo — essa informação é fornecida em um denso, embora rápido, resumo biográfico do autor presente no final do volume - é um velho conhecido dos interessados em política externa no Brasil, e pertence à atualíssima tradição política brasileira de pensadorespolíticos (ou melhor, de políticos-pensadores), de intelectuais que têm a oportunidade de aplicar na prática algumas de suas idéias, ou de, pelo menos, verificar na prática a validade de suas idéias, cujos mais notáveis exemplos são o próprio Presidente da República, o Ministro da Cultura e o ex-Ministro da Administração e Reforma do Estado.

Organizado em seis capítulos, o texto procura conferir inteligibilidade à política externa brasileira, tendo como referência básica a noção de "identidade". Assim, é por uma via conceitual, com a explicação sobre o relacionamento entre identidade e política externa, que se abre o volume. Em seguida, faz o autor uma retrospectiva histórica da $\mathrm{PEB}$, do que se ocupa nos capítulos intermediários do livro, tratando dos grandes temas e elementos da cada uma das fases de nossa política externa: formação territorial, desenvolvimento nacional, afirmação do "Brasil potência", globalização. A sequiência faz bastante sentido: após sabermos de onde viemos e onde estamos, devemos refletir sobre aonde vamos - e é exatamente nisso que consiste o capítulo final, dedicado a uma avaliação do cenário internacional contemporâneo, do cenário brasileiro atual e a uma discussão de como podemos nós, os brasileiros, agir no mundo globalizado.

Ao longo de todo o texto, algumas características da PEB tornam-se bastante evidentes, seja pela apresentação direta, seja por dedução a partir da leitura; são as características classicamente assinaladas da PEB: juridicismo, pacifismo, continuidade, coerência — em um conjunto por ele denominado de grociano. De fato, a narrativa de Lafer, além de bastante erudita (as indicações de livros e obras são várias, e fornecem referências valiosas), é convincente, pois chegamos à última página com a nítida impressão de termos uma diplomacia compenetrada de sua missão, conhecedora de sua história e dos desafios com que se defronta.

Nesse sentido - de elaborar uma narrativa coerente e inteligível de nossa história diplomática - Celso Lafer sai-se extremamente bem. Quando afirma desejar apresentar um resumo de suas meditações sobre a PEB, tanto do ponto de vista teórico quanto prático, é exatamente isso o que o leitor deve esperar, pois todas as idéias ali expostas já foram pensadas há muito. Além disso, a corporação diplomática brasileira é uma referência internacional, exatamente pelas características acima referidas: a prevalência do pacifismo é comprovada pela ausência de guerras latino-americanas em que o Brasil tivesse se envolvido desde o término da Guerra do Paraguai, em 1870; o juridicismo, por outro lado, é a outra face da moeda do pacifismo, caracterizando-se pela atuação brasileira e por sua ênfase nos acordos multilaterais, por sua validade como uma estruturação de um direito internacional; além disso, o insulamento burocrático característico do Itamaraty permite-lhe as características de continuidade e coerência de ação. 
Convém, todavia, não exagerarmos. Essas características da política externa brasileira, embora tradicionais, isto é, embora já fazendo parte de algo que poderíamos chamar de uma "tradição da diplomacia brasileira", não são sempre automáticas, nem têm uma idêntica aplicação ao longo do tempo. Mais do que outros gêneros de história, principalmente a diplomática registra as indeterminações tantas vezes já assinaladas para a política e para o fazer político. Além disso, cumpre notarmos que mesmo diplomatas já indicaram como esses traços da PEB não são "infalíveis" ou "automáticos" (ALMEIDA, 1998, especialmente cap. 5).

Essa interpretação da PEB, aliás, constitui-se em aspecto bastante ambíguo do texto, do ponto de vista intelectual, pois está exatamente demarcando a tensão entre o acadêmico e o político. Como pensador, as continuidades determinadas por Lafer são exageradas (sempre com a ressalva da necessidade de concisão do livro), não se justificando quer do ponto de vista histórico - a PEB teve muito mais oscilações e variações do que o opúsculo sugere —, quer do ponto de vista filosófico — pois esse continuísmo em nada se parece com a abertura histórica defendida por Hannah Arendt, autora que é, sem dúvida alguma, uma das grandes referências do atual Chanceler.

Por outro lado, a continuidade faz completo sentido se de fato percebemos o texto como um programa de ação, como uma longa peça introdutória explicativo-justificativa das posições a serem assumidas pelo autor em sua presente estada no Itamaraty.

Disso deriva também o que poderíamos chamar de teoria de relações internacionais implícita: claramente a perspectiva que o autor adota é a de um operador da política externa, de alguém que possui a responsabilidade de definir os termos nos quais a realidade internacional será traduzida, processada e nos quais as respostas nacionais serão formuladas.

Daí extraímos uma consequiência de caráter teórico, referente ao modelo analítico formulado por Lafer, decorrente da própria definição de identidade por ele proposta. Logo no início do livro o autor define que "o ponto de partida da construção da identidade coletiva, como observa Bovero, é a idéia de um bem ou interesse comum que leva pessoas a afirmarem uma identidade por semelhança, lastreada numa visão compartilhada deste bem ou interesse comum" (p. 15). Logo adiante, após considerar que são as experiências comuns de um povo frente a outro, das necessidades de um povo em contraposição com outro, o que confere o caráter internacional a essas relações, o autor afirma que o objetivo dessas relações é "ampliar o controle de uma sociedade sobre o seu destino". Ora, esses dados — "vida compartilhada por um povo", "necessidades internas em contraposição a externas", "solução de problemas internos" — são alguns dos traços definidores da perspectiva realista clássica da política internacional. Nessa linha de análise, o ator por definição é o Estado, que procura encaminhar as suas próprias demandas, em um cenário marcado pela multiplicidade de nações, cada qual gozando de determinadas características nacionais (isto é, de recursos de poder) ${ }^{1}$.

Por outro lado, na sequiência Celso Lafer comenta como a globalização vem diluindo as diferenças entre questões internas e externas, entre o que diz respeito estritamente a cada Estado nacional e ao que se refere a todos de modo geral: essa diluição, sem dúvida alguma, dificulta a tarefa dos policy-makers de elaborarem políticas públicas, pela dificuldade em determinarem quais são os problemas efetivamente internos e característicos ao país e o que não é; em outras palavras, em determinarem o já sempre problemático "interesse nacional" (p. 18-19).

Poder-se-ia pensar, então, na discussão de algo como o conceito de "sistema global multidimensional", elaborado recentemente por Villa $(1999 ; 2000)$ para dar conta da nova feição do sistema internacional, por meio de noções auxiliares como interdependência assimétrica, novos atores (ONGs, empresas multinacionais) etc. Sem dúvida alguma que Lafer toma como dados da realidade atual esses novos atores, os novos temas e toda a configuração internacional globalizada: entretanto, toma-os como dados da realidade apenas para reafirmar a centralidade e a posição fundamental do Estado, sem fazer maiores considerações sobre a complexidade que cerca, atualmente, a atuação específica desse mesmo Estado.

De qualquer forma, podemos nos perguntar: como é que efetivamente esse Estado brasileiro tem atuado

\footnotetext{
${ }^{1}$ Deixemos claro: o conceito de "escola realista" que adotamos aqui é amplo, definindo-se pela existência de vários Estados nação defendendo seus interesses nacionais (isto é, suasegurança) emumasituação de anarquia hobbesiana (ou seja, semuma autoridade superior capaz de impora ordempública), e conseqüentemente disputando o poder (qualquer que seja o fundamento deste).
} 
externamente?

Em primeiro lugar, podemos desde já perceber outra fonte de tensões. Por um lado, nossa "identidade nacional" define o Brasil como um país de tradições pacifistas, que procura colaborar na construção de uma ordem internacional mais harmônica e menos desigual para as diversas partes envolvidas. Por outro lado, como o próprio autor reconhece, "A diplomacia brasileira vem exercitando o potencial de geração de poder inerente ao papel de soft power no plano internacional, com o objetivo de assegurar espaço para a defesa dos interesses nacionais. $\mathrm{O}$ exercício deste papel gerador de soft power é, assim, um componente da nossa identidade internacional, voltado para o tema da estratificação internacional" (p. 77-78). Embora não o diga dessa forma, indubitavelmente uma das conseqüências desse soft power seria, por exemplo, a tão sonhada participação brasileira no Conselho de Segurança da ONU com direito a assento permanente, ao lado das grandes potências do mundo (baseadas, aliás, no hard power, de caráter militar).

Outro exemplo da mesma tensão. Ao comentar a importância de manter o Brasil relações cordiais (isto é, não-beligerantes) com seus vizinhos nos últimos 130 anos, desde o término da Guerra do Paraguai, como elemento de credibilidade e respeito junto à comunidade internacional — portanto, como criação do soft power via paficismo - o autor justifica a $1^{\text {a }}$ Reunião de Presidentes Sul-Americanos, realizada em Brasília em setembro de 2000. Sob o signo do pacifismo, afirma Lafer que "o objetivo da reunião foi o de aprofundar a cooperação já existente em nosso espaço comum, convertendo tal espaço num projeto. Este [...] tem como propósito ampliar a capacidade dos países da região no encaminhamento do desafio do desenvolvimento - tema comum e prioritário das agendas da política externa de todos" (p. 56). Ora, apesar da linguagem diplomática empregada - que, como sabemos, é sempre vazada em meios-termos, raramente de maneira categórica - que ninguém se iluda (como de fato ninguém se iludiu): mais que a "simples" busca de sinergia no subcontinente sul-americano, o encontro teve a importante função de afirmar explicitamente (embora nunca por meio de palavras) a liderança brasileira na região.

Há, aí, uma forte tensão: de um lado, uma postura de convergência e convencimento entre as diversas partes, a partir de uma leitura idealista defendida pelo discurso oficial; por outro lado, a aplicação de uma política de construção de poder, característica do realismo: é uma tensão entre o discurso e a prática. Ora, o senso comum da política, não poucas vezes cínico, pode perceber essa tensão como ilusória, pois o que conta na realidade são as ações, e não o discurso. O problema, todavia, está no fato de estarmos tratando não de "discurso oficial", que é, por assim dizer, uma entidade formalista e submetida a diversas exigências por vezes incompatíveis; como dizemos, não se trata aqui apenas do discurso oficial, mas, como afirma Lafer, da "identidade nacional", ou seja, do resultado das experiências públicas e particulares de toda a população brasileira, que se vêem traduzidas pela corporação diplomática em políticas externas. Supondo-se fiel a tradução da "identidade nacional" pelos nossos diplomatas, tanto em termos de percepção da realidade quanto em respostas a questões específicas, resulta daí uma contradição bastante complicada de ser solucionada, quase uma contradição dialética à la $\mathrm{Hegel}^{2}$.

De qualquer forma, não podemos deixar de comentar as observações de Lafer sobre um dos mais candentes temas da PEB, qual seja, a diplomacia a serviço do desenvolvimento. Provavelmente esse é o momento teórico mais alto e interessante do livro, pois é exatamente o objeto de reflexão por excelência de Lafer, além de ser o eixo básico de condução da PEB desde os idos de 1930. Infelizmente com muita rapidez, o autor apresenta alguns conceitos como "nacionalismo de fins", "autonomia pela distância", "polaridades definidas pelos eixos Leste/Oeste e Norte/Sul”, cujo poder explicativo para nossa história diplomática — e, dado o caráter instrumental que ela possui, para nossa história política de modo geral — é muito grande. Ainda que não concordemos com todos os seus termos, seu valor científico destaca-se para o observador atento - quem sabe por serem essas passagens menos "políticas" e mais científicas.

A passagem da "diplomacia do desenvolvimento" para o momento seguinte, da "diplomacia da globalização", está um pouco truncada no texto, isto é, não há uma justificativa teórica para a mudança. Assim, ela é fundamentada pelo autor como uma necessidade dos fatos, ou seja, o mundo mudou e uma nova política é

2 Cabe notarmos que esse traço "esquizofrênico" daPEB já fôra percebido e criticado por outro autor, Albuquerque (1999), que o considerou como um problema de radical não-adequação entre a maneira como nossos diplomatas percebema si próprios e ao ambiente intemacional, como reagema esse sistema, e como percebem, depois, sua reação. 
necessária. A mudança de referência, entretanto, não é de pouca monta. A "diplomacia do desenvolvimento" foi inaugurada na década de 1930 com Getúlio Vargas, tendo o desenvolvimento nacional como um de seus valores fundamentais, daí extraindo diversas conseqüências políticas - a começar pela instrumentalização das relações externas para o desenvolvimento nacional (de que a implantação da Companhia Siderúrgica Nacional é o exemplo maior e momento fundante). Juntamente com o nosso estilo diplomático - pacifismo, juridicismo, busca da eqüidade internacional —, o desenvolvimentismo foi, durante seis décadas, um dos elementos "permanentes" da PEB, adotado mais ou menos por todos os governos posteriores a 1930.

Por outro lado, a "diplomacia da globalização" é mais "formal" que substantiva, ou seja, é mais uma forma de lidar com os problemas, além de uma postura frente à realidade, que, também, a postulação da importância de determinadas questões internacionais: "“...] o mais significativo desafio que se coloca para a política externa brasileira neste início de século XXI é o de como preservar um espaço próprio, no plano interno, para poder lidar com o impacto dos tempos da 'internalização' do mundo [...]” (p. 122).

Não sejamos saudosistas: não se trata aqui de defender um retorno ao modelo antigo. Evidentemente que se os dados da realidade mudam, o comportamento deve adequar-se: o problema está na justificativa que o "intelectual" apresenta para ela (ou que deixa de apresentar). Haja vista a importância que o tema do desenvolvimento teve — e ainda tem — para o Brasil (ou melhor, para a "identidade nacional do Brasil"), uma discussão sobre a passagem de um modelo para outro seria bastante conveniente.

A ambigüidade político-intelectual, que, como vimos, perpassa todo esse opúsculo, torna-se mais compreensível se o lermos como as perspectivas de alguém que assume um Ministério - cuja memória institucional é uma das mais bem-conservadas no Brasil — de um governo decidido a marcar sua presença em nível internacional. Nisso está uma das lacunas maiores do livro, pois ele refere-se mais propriamente às variáveis internas da PEB, isto é, como em cada conjuntura os atores nacionais — os diplomatas e o Presidente da República - agiram sobre sua situação internacional, que a uma proposta mais concreta de atuação no cenário internacional com que presentemente se depara. Talvez, de acordo com o estilo diplomático de se expressar, não uma afirmação categórica, mas uma sutil, subliminar insinuação de um ethos; ao invés de políticas e projetos determinados e certos, um estilo de atuação, cujas grandes características seriam percebidas ao longo do texto.

Nesse sentido, o livro é específico para consumo interno, escrito com o objetivo de apresentar ao público as opiniões que o Chanceler tem sobre a atuação do Ministério que chefia.

Recebida para publicação em 20 de novembro de 2001. Resenha aprovada em 26 de novembro de 2001.

Gustavo Biscaia de Lacerda (gustavobiscaia@yahoo.com.br) é bacharel em Ciências Sociais pela Universidade Federal do Paraná (UFPR).

\section{REFERÊNCIAS BIBLIOGRÁFICAS}

ALBUQUERQUE, J. A. G. 1999. A nova geometria do poder mundial nas visões argentina e brasileira. Conferência proferida no $2^{\circ}$ Seminário Brasil-Argentina, realizado no Rio de Janeiro, em 10 e 11 de junho. www.mre.gov.br/ipri/SBArgentina2.html : 16 de novembro de 1999.

ALMEIDA, P. R. 1998. Relações internacionais e politica externa do Brasil. Porto Alegre : Editora da Universidade.

VILLA, R. A. D. 1999. Formas de influência das ONGs na política internacional contemporânea. Revista de Sociologia e Política, Curitiba, n. 12, p. 21-33, jun.

. 2000. Segurança global multidimensional. São Paulo : Annablume. 